\title{
Stereotactic Body Radiotherapy Versus Intensity-Modulated Radiotherapy For Hepatocellular Carcinoma With Portal Vein Tumor Thrombosis
}

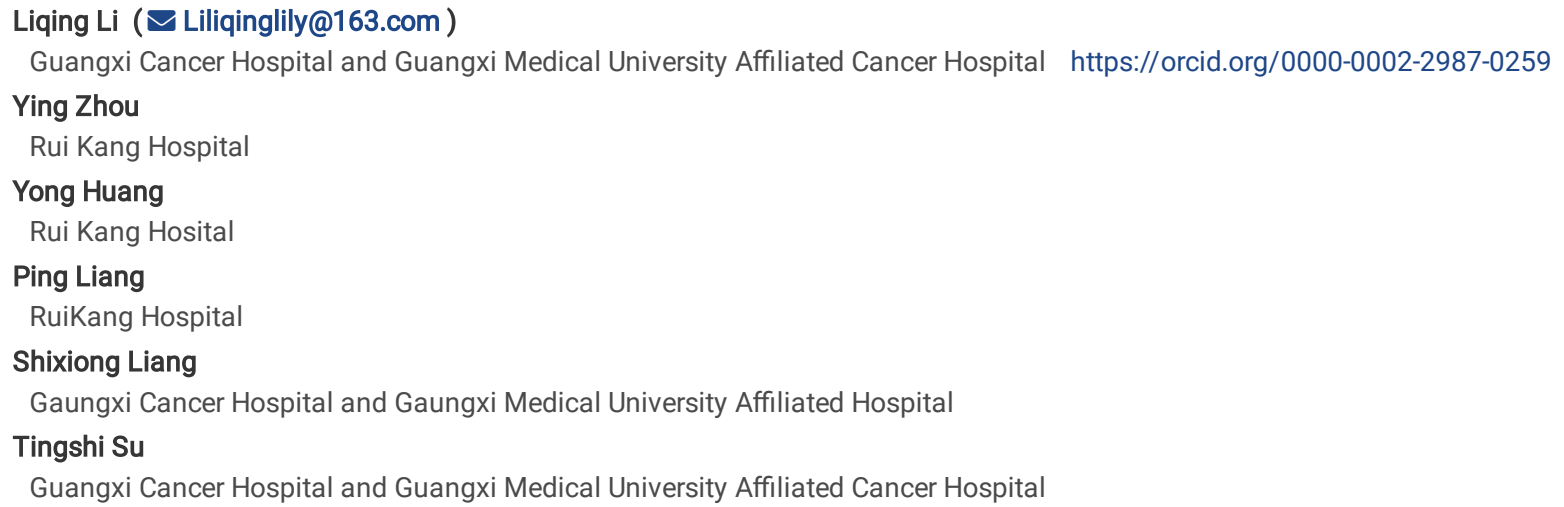

Keywords: Primary liver cancer, Hepatic malignancy, Macrovascular invasion, Portal vein invasion, Barcelona Clinic Liver Cancer staging C, locally advanced, Radiotherapy, Treatment outcome, Survival, Tumor control

Posted Date: February 15th, 2021

DOI: https://doi.org/10.21203/rs.3.rs-178882/v1

License: (c) (1) This work is licensed under a Creative Commons Attribution 4.0 International License. Read Full License

Version of Record: A version of this preprint was published at Hepatology International on April 5th, 2021. See the published version at https://doi.org/10.1007/s12072-021-10173-y. 


\section{Abstract}

Background: It is unclear whether robotic stereotactic body radiotherapy (SBRT) is superior to intensity-modulated radiotherapy (IMRT) in advanced hepatocellular carcinoma (HCC). This study aimed to compare the long-term outcomes of SBRT with those of IMRT in HCCs with portal vein tumor thrombosis (PVTT).

Methods: We retrospectively evaluated 287 HCC patients with PVTT who underwent radiotherapy between January 2000 and January 2017 . Of them, 154 and 133 patients were treated with IMRT and SBRT, respectively. Overall survival (OS), progression-free survival (PFS), intrahepatic control (IC), and local control (LC) were evaluated in univariable and propensity-score matched analyses.

Results: After matching, 102 well-paired patients were selected. There was no significant difference in the 6-, 12-, 24-, and 60-month cumulative 0S (73.5, 42.9, 23.6, 7.6\% vs. 72.4, 45.1, 29.8, 13.2\%, P=0.151), PFS (53.9, 29.3, 21.8, 7.5\% vs. 54.5, 19.3, 12.0, 9.6\%, P=0.744) , IC (61.4, 45.7, 39.0, 26.8\% vs. 75.1, 45.8, 35.9, $28.7 \%, \mathrm{P}=0.144)$, and LC $(85.2,56.5,52.1,47.4 \%$ vs. 87.4, 65.2, 62.1, 62.1\%, $\mathrm{P}=0.191)$ between the IMRT and SBRT groups. A biologically effective dose assumed at an $\mathrm{a} / \mathrm{b}$ ratio of $10\left(\mathrm{BED}_{10}\right)$ of $\geq 100 \mathrm{~Gy}$ was the optimal cutoff for predicting the OS, PFS, IC, and LC in the patients who received SBRT.

Conclusions: When high-precision tracking technology is available, SBRT appears to be a safe and more time-efficient treatment, achieving comparable OS, PFS, IC and LC to IMRT for local advanced HCC with PVTT. A BED $10 \geq 100$ Gy is recommended if tolerated by normal tissue.

\section{Introduction}

Hepatocellular carcinoma (HCC) is the fourth most common cause of cancer-related death worldwide [1]. Approximately $10-40 \%$ of patients with HCC have portal vein tumor thrombosis (PVTT) at diagnosis, classified as Barcelona Clinic Liver Cancer (BCLC)-C stage). If left untreated, the median survival time of HCC patients with PVTT is only 2.7-4.0 months [2]. Over the past decade, sorafenib has been the recommended first-line treatment for advanced HCC patients with BCLC-C stage [3]. However, the outcomes of these patients treated with sorafenib remains poor, with an extended survival of only $1.5-4.0$ months [4, 5]. Radiotherapy, such as three-dimensional radiotherapy and intensity-modulated radiotherapy (IMRT), has been increasingly applied in advanced HCC management. A randomized clinical trial by Yoon et al. [6] showed superior efficacy of trans-arterial chemoembolization (TACE) plus RT to sorafenib in HCC patients with PVTT, with significantly extended overall survival (OS). Treatment guidelines in the Asian region, such as in Korea and China, recommend radiotherapy as treatment for PVTT $[7,8]$.

Stereotactic body radiation therapy (SBRT) achieves encouraging outcomes comparable to those of liver resection, radiofrequency ablation, and TACE in early stage HCC[9-11]. For advanced HCC, Bettinger et al.[12] reported a considerable survival benefit of SBRT compared to sorafenib, extending OS to a median of 9.3 months. However, it is unclear whether SBRT is also superior to IMRT in advanced HCC. Thus, this study aimed to compare the long-term outcomes of SBRT with those of IMRT in advanced HCC with PVTT.

\section{Materials And Methods}

\section{Study design and patients}

This was a retrospective study of advanced HCC patients with PVTT who underwent external radiation therapy in China. The patients who underwent IMRT in Cancer Hospital during January 2000-January 2017 and the patients who underwent SBRT in Rui Kang Hospital during January 2009-January 2017 were included. The eligibility criteria were as follows: (1) advanced HCC with PVTT diagnosed via histopathology or according to the clinical criteria for HCC diagnosis [8]; (2) Eastern Cooperative Oncology Group score 0-2; (3) Child-Pugh class A (CP-A) or B (CP-B), (4) no concurrent systemic treatments, and (5) Patients with TACE-refractory disease were included.

\section{Radiotherapy protocol}

Hypofractionated intensity-modulated radiation therapy

All patients underwent plain and contrast-enhanced computed tomography (CT) scans in the supine position with both arms raised above the head for RT planning. Vacuum molds were used for patient immobilization. The CT images were acquired at 3-mm slice thickness in free quiet breathing mode. All target areas were sketched in the MIM 6.8 system (MIM, USA), and IMRT plans were generated using Pinnacle 3 system (Philips, Netherlands). The patients underwent hypofractionated IMRT using a linear accelerator with 6 MV X-rays (ELEKTA Synergy, Sweden).

Computerized tomography-magnetic resonance imaging (CT-MRI) fusion was performed to clearly show the intrahepatic lesion. The gross tumor volume (GTV) was defined by the hyperdense area of the intrahepatic primary tumor during the arterial phase and the hypodense filling defect area of the venous thrombus including PVTT during the venous phase. The clinical target volume (CTV) was $4-5 \mathrm{~mm}$ larger than the diameter of the tumor area and the distal end of the venous thrombus.

The planning target volume (PTV) was defined as the CTV plus an asymmetric 1-cm expansion in the cranial caudal direction and 5-mm axially for setup uncertainty and respiratory motion. For both IMRT and SBRT, the PVTT was treated with same dose as the primary tumor in the same patient. Hypofractionation was performed every other day (3 fractions a week). The final median radiation dose delivered to the isocenter was $51 \mathrm{~Gy}$ (range, $30-60$ Gy), with a median per dose of $4 \mathrm{~Gy}$ (range, 2.5-7 Gy) and a median fraction of 12 (range, 7-20). The median total irradiation time was 25 days (range, $15-$ 50 days). 
The fraction doses were determined according to the following principles: 3 to $5 \mathrm{~Gy} /$ fraction for tumors larger than $5 \mathrm{~cm}$ in diameter and/or $\mathrm{CP}$-B and more than 5 to $6 \mathrm{~Gy} /$ fraction for tumors less than $5 \mathrm{~cm}$ in diameter and/or CP-A. The dose is usually limited to $30-45 \mathrm{~Gy}$ for CP-B patients.

\section{Stereotactic body radiation therapy}

SBRT was delivered using the CyberKnife system (Accuray Inc., Sunnyvale, CA, USA) with tracking of liver motion using implanted fiducials. The simulation CT scan process and motion management were the same as those for IMRT. Seven days prior to the CT scan or MRI (slice thickness, 3 mm), 3 to 4 fiducials (diameter, $0.8 \mathrm{~mm}$ ) were inserted into tumor tissue or into the surrounding area of the tumor under B-ultrasound or CT guidance. The definition of GTV was similar as that for the IMRT technique, and the CTV was equivalent to the gross tumor volume. GTV was expanded by 3-5 mm to establish the planning target volume (PTV), and this was usually decreased manually when the dose-limiting organs overlapped.

SBRT was performed on consecutive days. The final median radiation dose delivered was $42 \mathrm{~Gy}$ (range, 30-50 Gy), with a median per dose of $11 \mathrm{~Gy}$ (range, 7-15 Gy) and a median fraction of 4 (range, 3-5) with the median $66 \%$ (range, $60-80 \%$ ) isodose line, which covered $>97 \%$ PTV. The dose is usually limited to less than 30-40 Gy for CP-B patients. For all cases in both groups, the total dose was determined by the volume of the normal liver, CP-class, and the maximum dose to the stomach or duodenum. Treatment delivery and dose-volume constraints for organs at risk are shown in Table S1.

\section{Response evaluation and follow-up}

Patients was re-evaluated 1 month after treatment and subsequently every 3 or 6 months. Follow-up laboratory examinations included levels of alanine transaminase, aspartate transaminase, prothrombin time (PT), total bilirubin, albumin, and alpha-fetoprotein (AFP). Follow-up assessments also included CT or MRI at 1 month after the procedure and every 3 to 6 months thereafter.

Classic radiation-induced liver disease (c-RILD) was defined as an anicteric elevation in alkaline phosphatase levels of at least twofold the upper normal level and/or anicteric hepatomegaly and/or ascites within 2 weeks to 3 months after RT. Non-classic radiation-induced liver disease (nc-RILD) was defined as an elevation of liver transaminases more than 5 times the upper limit of normal or changes in CP class of $\geq 2$ points within 3 months after RT. Patients with toxicity due to liver tumor progression were excluded.

\section{Statistical analysis}

Cumulative OS, progression-free survival (PFS), intrahepatic control (IC), and local control (LC) were calculated using the Kaplan-Meier method and compared using the log-rank test. OS was evaluated from the date of the first radiotherapy treatment to the date of any-cause death or the last follow up. PFS was evaluated from the date of the first treatment to the date of any tumor recurrence, progression, or death or the date of censoring. IC was evaluated from the date of the first treatment to the date of intrahepatic failure (defined as the reappearance of radiologic hallmarks of HCC in the whole parenchyma of the liver including in- and out-field-treated lesions) or the date of censoring. LC was evaluated from the date of the first treatment to the date of infield recurrence. Categorical variables were compared using the Pearson's chi-squared test, while continuous variables were compared using the Wilcoxon rank-sum test. Univariate and multivariate analyses were performed with the Cox proportional hazards model. The receiver operating characteristic (ROC) curve analysis was performed to determine the best cutoff value of $\mathrm{BED}_{10}$ for the prediction of OS, PFS, LC, and IC.

To reduce potential selection bias and confounding effects of treatment, propensity score matching analysis (PSM) was applied. Patients in the SBRT and IMRT groups were matched in a 1:1 ratio using the nearest neighbor matching algorithm with a caliper of 0.2 without replacement. The propensity scores were calculated using logistic regression model including the following variables: age, sex, bilirubin-albumin (ALBI) score, TACE, PT, alpha fetoprotein level, and tumor size.

All statistical analyses were performed using R version 4.0.2 (2020-06-22) software. $\mathrm{P}<.05$ was considered statistically significant.

\section{Results}

\section{Patient characteristics}

Overall, 287 patients were evaluated. Of them, 214 (74.6\%) patients died, and 73 patients were right-censored. Table 1 shows the baseline characteristics of the SBRT group $(n=133)$ and the IMRT group $(n=154)$. Before propensity score matching, the proportion of patients with unfavorable baseline characteristics was higher in the SBRT group than that in the IMRT group, including TACE refractory disease, older age, PT, albumin, ALBI score, and ALBI grade (all P<0.05). After matching, 102 paired patients from the SBRT and IMRT groups were selected. The patient characteristics were well balanced between the two groups in the matched cohort.

\section{Overall survival, progression-free survival, intrahepatic control, and local control}

The median follow-up time was 31 months (range, 3-84 months). Before propensity score matching, the median OS in the IMRT and SBRT groups was 10.0 vs. 10.0 (HR=0.893; 95\% Cl: 0.677-1.178; P = 0.422) months; PFS, 6.0 vs. 6.0 (HR=1.103; 95\% Cl: 0.855-1.422; P =0.450) months; IC, 9.0 vs. 11.0 (HR=1.269; $95 \% \mathrm{Cl}: 0.792-2.035 ; \mathrm{P}=0.322)$ months. There was no significant difference between the IMRT group and the SBRT group with respect to the 6-, $12-, 24-$, and 60-month cumulative OS (73.2, 48.1, 25.1, 10.7\% vs. 70.3, 46.5, 29.3, 11.3\%, P=0.407; Figure 1a), PFS (52.3, 30.6, 20.7, 8.7\% vs. 51.3, 21.6, 10.0, 8.3\%, P=0.424; Figure 1b), IC (61.8, 44.3, 35.6, 26.0\% vs. 75.4, 46.3, 33.0, 26.4\%, P=0.094; Figure1c), and LC (84.5, 62.6, 58.1, 52.7\% vs.87.0, 64.8, 54.6, 54.6\%, $\mathrm{P}=0.498$; Figure1d). 
Consistent results of no statistically significant difference in OS, PFS, IC, and LC were obtained after propensity score matching (Figure $\mathbf{2 a}, \mathbf{2 b}, \mathbf{2 c}, \mathbf{2 d}$ ). The median OS, PFS, and IC was 8 vs. 10 (HR=0.795; Cl: 0.574-1.099; P=0.165), 6 vs. 6 (HR=1.048; Cl: 0.776-1.415; P=0.758), and 8 vs. 11 (HR=0.756; Cl: 0.5121.116; $P=0.159)$ months in the IMRT and SBRT groups. The 6-, 12,- 24-, and 60-month cumulative OS $(73.5,42.9,23.6,7.6 \%$ vs. $72.4,45.1,29.8,13.2 \%$, $\mathrm{P}=0.151$; Figure2a), PFS (53.9, 29.3, 21.8, 7.5\% vs. 54.5, 19.3, 12.0, 9.6\%, $\mathrm{P}=0.744$; Figure2b), IC (61.4, 45.7, 39.0, 26.8\% vs. 75.1, 45.8, 35.9, 28.7\%, $\mathrm{P}=0.144$; Figure2c), and LC $(85.2,56.5,52.1,47.4 \%$ vs. $87.4,65.2,62.1,62.1 \%, P=0.191$; Figure $2 d)$ rates of the IMRT group were similar to those of the SBRT group.

Multivariate survival analysis in the matched cohort (Online Resource: Table S2) showed that the AFP level (HR=1.433; 95\% Cl: 0.928-2.214; $P=0.023)$ and ALBI score (HR=1.860; 95\% Cl: 1.298-2.665; $\mathrm{P}=0.004)$ were independent predictors of OS. Further, ALBI score $(\mathrm{HR}, 1.609 ; 95 \% \mathrm{Cl}, 1.154-2.244 ; \mathrm{P}=0.005)$ was an independent predictor of PFS.

\section{Subgroup analysis bybiologically effective dose}

Univariable survival analysis showed that $\mathrm{BED}_{10}$ was a prognostic factor for OS, PFS, IC, and LC. BED 10 was excluded from multivariate analysis to avoid collinearity). Therefore, we further performed subgroup analyses by BED $_{10}$. No optimal cutoff value was found in ROC analyses for the IMRT group. In ROC analyses of the matched cohort, the optimal cutoff for predicting OS, PFS , IC and LC of the SBRT group was 100 Gy (AUC=0.601, Online Resource: Figure S1a), 100 Gy (AUC=0.670; Online Resource: Figure S1b), 100 Gy (AUC=0.601; Online Resource: Figure S1c), and 100 Gy (AUC=0.598; Online Resource: Figure S1d), respectively. Therefore, the prognostic effect of $B E D_{10} \geq 100$ Gy for the OS, PFS, IC, and LC in the SBRT group was further investigated.

In Kaplan-Meier analyses of the unmatched cohort, the 6-, 12-, 24-, and 60- month OS (87.5\%, $61.5 \%, 46.2 \%$, and $46.2 \%$ vs. $63 \%$, $36.5 \%, 22.6 \%$, and $8.5 \%$; $P=0.0078$; Figure 3a), PFS (66.9\%, 46\%, 30.7\%, and $30.7 \%$ vs. $38.8 \%, 15.6 \%, 5.4 \%$, and $3.6 \%$; $P=0.0011$; Figure 3 b), IC (90.9\%, $69.2 \%, 60.6 \%$, and $60.6 \%$ vs. $62.8 \%, 40.1 \%, 25.5 \%$, and $17 \%$; $P=0.0059$; Figure 3 c), and LC (95.5\%, 86.8\%, 77.1\%, 77.1\% vs. 84.7\%, 58.0\%, 47.0\%, $47.0 \%, 17 \%$; $P=0.04$; Figure 3 d) were significantly better in patients treated with a high $B E D_{10}$ level $\left(B D_{10} \geq 100 \mathrm{~Gy}\right)$ than in patients with a low $B E D_{10}$ level $\left(B D_{10}<100 \mathrm{~Gy}\right)$. The results of $R O C$ analyses and Kaplan-Meier analyses with a $\mathrm{BED}_{10}$ cutoff value of $100 \mathrm{~Gy}$ are shown in Online Resource:Table S3.

\section{Toxicity}

In the matched IMRT group, 15 (14.7\%) patients experienced RILD (c-RILD, n=2; nc-RILD with elevation of CP-score $\geq 2$, n =13). Of them, 6 (6/89 with CP-A, 6.7\%) and 9 (9/13 with CP-B, 69.2\%) had CP-A and CP-B disease, respectively. Five patients died within 2 months and 2 died within 5-6 months due to RILD after IMRT. There were 4 patients (3.9\%) with tumor adjacent to the gastrointestinal tract $(<1 \mathrm{~cm})$ who experienced radiation-induced gastrointestinal (GI) bleeding within 5-6 months.

In the matched SBRT group, 12 (11.8\%) patients developed RILD (c-RILD, n=2; nc-RILD with elevation of CP-score $\geq 2$, n=10). Of them, 5 (5/91 with CP-A, 5.4\%) and 7 (7/11 with CP-B, 63.6\%) had CP-A and CP-B disease, respectively. Among the patients who received BED $10 \geq 100$ Gy, 4 patients (1 with CP-A5, 3 with CPA6) treated with $42-45$ Gy in 3 fractions experienced nc-RILD with elevation of CP-score $\geq 2$ after SBRT. Among the patients who received $B E D_{10}<100$ Gy group, 2 patients with CP-B7 died within 3 and 5 months due to c-RILD after SBRT, and 3 patients (2.9\%) with tumors adjacent to the gastrointestinal tract (<1 $\mathrm{cm}$ ) experienced radiation-induced GI bleeding within 4-7 months.

\section{Discussion}

With the improvement of precision radiotherapy techniques, robotic SBRT was widely used in the treatment of HCC. In the current study, SBRT achieved higher BED within fewer fractions and a shorter duration of treatment than IMRT but obtained comparable OS, PFS, IC, and LC. To our best knowledge, this is the first study to directly compare the efficacy of SBRT with that of hypofractionated IMRT in the treatment of HCC.

Our results in both groups compared favorably to the published literatures [12-21] (Table 2). The comparability of PFS and OS in our study may be because the therapeutic effect is actually the same, and not the artificial result of particularly poor or excellent IMRT and SBRT procedures. Similarly, Rim et al. [22] reported a comparable 1-year OS between 3-dimensional conformal RT and SBRT (48.5\% vs 46.5\%). Yang et al [18] also showed a considerable survival benefit in SBRT compared to RT (1- and 2-year OS: $33.1 \%$ and $16.5 \%$ vs. $17.3 \%$ and $5.2 \%$ ) in 140 patients with advanced HCC with PVTT. Consequently, it is plausible that SBRT is feasible for patients with PVTT, with acceptable toxicity and survival outcomes.

In the current study, the SBRT group received significantly higher $\mathrm{BED}_{10}$ than did the IMRT group (median: 89.7 Gy vs. $72.8 \mathrm{~Gy}$ after matching, $\mathrm{P}<0.001$ ). Further, $\mathrm{BED}_{10} \geq 100 \mathrm{~Gy}$ was a favorable predicator of OS, PFS, IC, and LC for patients who underwent SBRT, while no optimal BED cutoff was identified for the IMRT group. After propensity score matching, 41 (40.2\%) patients in the SBRT group experienced intrahepatic progression. The patients receiving $B E D_{10} \geq 100$ Gy achieved better intrahepatic control and local control, along with better OS, PFS in the SBRT group, while the incidence of RILD in the BED $\geq 100 G y$ group had no significant difference from that in the BED<100Gy group ( $4 / 25$ vs. 8/108, $P=0.228)$. BED $10 \geq 100$ Gy was used to be considered as radiation "ablation" and associated with improved outcomes in multiple prior studies of $\mathrm{HCC}<5 \mathrm{~cm}[23]$. Our previous results also showed that an escalated dose (BED $10 \geq 100 \mathrm{~Gy})$ was a significant prognostic factor for $\mathrm{HCC}>5 \mathrm{~cm}$ [24]. Scorsetti et al. [25] also reported that the 2-year in-field local control (100\% vs $87 \%$ ) and PFS (52.5\% vs 17.3\%) was higher for BED $\geq 100$ Gy than for <100 Gy. In a large-scale study of 456 patients by Robbins et al. [26], the median and 1-year OS were 15.3 months and $56.6 \%$ for BED $\leq 75$ Gy, 18.3 months and $67.5 \%$ for BED $>75$ Gy and $\leq 100$ Gy, and 37.2 months and $81.4 \%$ for BED $>100$ Gy. In summary, our results may provide the rationale for using high BED ( $\left.\mathrm{BED}_{10} \geq 100 \mathrm{~Gy}\right)$ SBRT to treat HCC patients with PVTT if tolerated by normal tissue.

The toxicities were tolerable in both groups, and there was no difference in the rate of RILD (15/102 [14.7\%] vs. 12/102 [11.8\%], Chi-square P=0.5). Our previous studies shown V15 $\leq 21.5 \%$ and/or the absolute liver volume spared from at less 10 Gy (Vs10) $\geq 621.8 \mathrm{~mL}$ could improve the safety of SBRT in the treatment of HCC[27]. For hypofractionated treatment, mean normal liver doses of $<23$ Gy and/or V $20<48.5 \%$ were crucial for reducing the risk of RILD [28,

Page 4/11 
29]. According to our previous experience, patients with CP-B class are at higher risk of RILD than those with CP-A; consistent findings were obtained in this study $(16 / 24[66.6 \%]$ vs. $11 / 180[6.1 \%]$, Chi-square $P=0.000)$. Xu et al. [30] also reported a lower hepatic tolerable dose (TD5) from a mean normal liver dose of 6 Gy for Child-Pugh B compared to 21 Gy for Child-Pugh A patients.

We have to acknowledge some limitations of our study. First, this was a retrospective and non-randomized study. Second, selection bias may have increased given the long study duration of 17 years (2000-2017). Third, we cannot account for the unknown differences between the two groups, such as the institutional experience, and the patient's financial capacity. Further randomized prospective clinical trials are warranted to provide robust conclusions.

\section{Conclusions}

When high-precision tracking technology is available, SBRT appears to be a safe and more time-efficient treatment, achieving comparable OS, PFS, IC and LC to IMRT for local advanced HCC with PVTT. A BED $10 \geq 100$ Gy is recommended if tolerated by normal tissue.

\section{Declarations}

Funding: This research was supported by the National Natural Science Foundation of China (81903257), Guangxi Natural Science Foundation (CN) (2020JJA140141), China International Medical Foundation-Tumor Precise Radiotherapy Spark Program (2019-N-11-01), Guangxi Medical University Training Program for Distinguished Young Scholars, and Guangxi BaGui Scholars' Special Fund.

Conflicts of Interest: The authors declare no conflict of interest.

Ethics approval and consent to participate: The study design was approved by the ethics review board of Guangxi Medical University Cancer Hospital (LW2020036). The requirement of written informed consent for participation was waived owing to the retrospective nature of the study.

\section{Consent for publication: Not applicable.}

Availability of data and codes: The statistical datasets and codes used and/or analyzed in the current study are available from the corresponding author (sutingshi@163.com) on reasonable request.

Author Contributions: Data curation, Ying Zhou, Yong Huang, Ping Liang, and Ting-Shi Su; Formal analysis, Li-Qing Li, Shi-Xiong Liang, and Ting-Shi Su; Funding acquisition, Ting-Shi Su; Writing - original draft, Li-Qing Li and Ting-Shi Su; Writing - review \& editing, Shi-Xiong Liang and Ting-Shi Su.

\section{References}

1. Yang JD, Hainaut P, Gores GJ, Amadou A, Plymoth A, Roberts LR: A global view of hepatocellular carcinoma: trends, risk, prevention and management. Nat Rev Gastroenterol Hepatol 2019, 16(10):589-604.

2. Schoniger-Hekele M, Muller C, Kutilek M, Oesterreicher C, Ferenci P, Gangl A: Hepatocellular carcinoma in Central Europe: prognostic features and survival. Gut 2001, 48(1):103-109.

3. Llovet JM, Ricci S, Mazzaferro V, Hilgard P, Gane E, Blanc JF, de Oliveira AC, Santoro A, Raoul JL, Forner A et al: Sorafenib in advanced hepatocellular carcinoma. N Engl J Med 2008, 359(4):378-390.

4. Bruix J, Raoul JL, Sherman M, Mazzaferro V, Bolondi L, Craxi A, Galle PR, Santoro A, Beaugrand M, Sangiovanni A et al: Efficacy and safety of sorafenib in patients with advanced hepatocellular carcinoma: subanalyses of a phase III trial. J Hepatol 2012, 57(4):821-829.

5. Cheng AL, Guan Z, Chen Z, Tsao CJ, Qin S, Kim JS, Yang TS, Tak WY, Pan H, Yu S et al: Efficacy and safety of sorafenib in patients with advanced hepatocellular carcinoma according to baseline status: subset analyses of the phase III Sorafenib Asia-Pacific trial. Eur J Cancer 2012, 48(10):1452-1465.

6. Yoon SM, Ryoo BY, Lee SJ, Kim JH, Shin JH, An JH, Lee HC, Lim YS: Efficacy and Safety of Transarterial Chemoembolization Plus External Beam Radiotherapy vs Sorafenib in Hepatocellular Carcinoma With Macroscopic Vascular Invasion: A Randomized Clinical Trial. JAMA Oncol 2018, 4(5):661669.

7. Korean Liver Cancer A, National Cancer Center GK: 2018 Korean Liver Cancer Association-National Cancer Center Korea Practice Guidelines for the Management of Hepatocellular Carcinoma. Korean J Radiol 2019, 20(7):1042-1113.

8. Zhou J, Sun HC, Wang Z, Cong WM, Wang JH, Zeng MS, Yang JM, Bie P, Liu LX, Wen TF et al: Guidelines for Diagnosis and Treatment of Primary Liver Cancer in China (2017 Edition). Liver Cancer 2018, 7(3):235-260.

9. Su TS, Liang P, Liang J, Lu HZ, Jiang HY, Cheng T, Huang Y, Tang Y, Deng X: Long-Term Survival Analysis of Stereotactic Ablative Radiotherapy Versus Liver Resection for Small Hepatocellular Carcinoma. Int J Radiat Oncol Biol Phys 2017, 98(3):639-646.

10. Su T-S, Liang P, Zhou Y, Huang Y, Cheng T, Qu S, Chen L, Xiang B-D, Zhao C, Huang D-J et al: Stereotactic Body Radiation Therapy vs. Transarterial Chemoembolization in Inoperable Barcelona Clinic Liver Cancer Stage a Hepatocellular Carcinoma: A Retrospective, Propensity-Matched Analysis. Frontiers in Oncology 2020, 10(347).

11. Wahl DR, Stenmark MH, Tao Y, Pollom EL, Caoili EM, Lawrence TS, Schipper MJ, Feng M: Outcomes After Stereotactic Body Radiotherapy or Radiofrequency Ablation for Hepatocellular Carcinoma. J Clin Oncol 2016, 34(5):452-459.

12. Bettinger D, Pinato DJ, Schultheiss M, Sharma R, Rimassa L, Pressiani T, Burlone ME, Pirisi M, Kudo M, Park JW et al: Stereotactic Body Radiation Therapy as an Alternative Treatment for Patients with Hepatocellular Carcinoma Compared to Sorafenib: A Propensity Score Analysis. Liver Cancer 2019, 8(4):281294. 
13. Kim JY, Yoo EJ, Jang JW, Kwon JH, Kim KJ, Kay CS: Hypofractionated radiotheapy using helical tomotherapy for advanced hepatocellular carcinoma with portal vein tumor thrombosis. Radiat Oncol 2013, 8:15.

14. Chen SW, Lin LC, Kuo YC, Liang JA, Kuo CC, Chiou JF: Phase 2 study of combined sorafenib and radiation therapy in patients with advanced hepatocellular carcinoma. Int J Radiat Oncol Biol Phys 2014, 88(5):1041-1047.

15. Hou JZ, Zeng ZC, Wang BL, Yang P, Zhang JY, Mo HF: High dose radiotherapy with image-guided hypo-IMRT for hepatocellular carcinoma with portal vein and/or inferior vena cava tumor thrombi is more feasible and efficacious than conventional 3D-CRT. Jpn J Clin Oncol 2016, 46(4):357-362.

16. Im JH, Yoon SM, Park HC, Kim JH, Yu JI, Kim TH, Kim JW, Nam TK, Kim K, Jang HS et al: Response to Is radiotherapy the best option for treating hepatocellular carcinoma with PVTT? Liver Int 2017, 37(2):308-309.

17. Xi M, Zhang L, Zhao L, Li QQ, Guo SP, Feng ZZ, Deng XW, Huang XY, Liu MZ: Effectiveness of stereotactic body radiotherapy for hepatocellular carcinoma with portal vein and/or inferior vena cava tumor thrombosis. PLoS One 2013, 8(5):e63864.

18. Yang JF, Lo CH, Lee MS, Lin CS, Dai YH, Shen PC, Chao HL, Huang WY: Stereotactic ablative radiotherapy versus conventionally fractionated radiotherapy in the treatment of hepatocellular carcinoma with portal vein invasion: a retrospective analysis. Radiat Oncol 2019, 14(1):180.

19. Chopra S, George K, Engineer R, Rajamanickam K, Nojin S, Joshi K, Swamidas J, Shetty N, Patkar S, Patil P et al: Stereotactic body radiotherapy for inoperable large hepatocellular cancers: results from a clinical audit. Br J Radiol 2019, 92(1101):20181053.

20. Liu HY, Lee Y, McLean K, Leggett D, Hodgkinson P, Fawcett J, Mott R, Stuart K, Pryor D: Efficacy and Toxicity of Stereotactic Body Radiotherapy for Early to Advanced Stage Hepatocellular Carcinoma - Initial Experience From an Australian Liver Cancer Service. Clin Oncol (R Coll Radiol) 2020, 32 (10):e194-e202.

21. Yadav HP, Kumar R, Gupta A, Thaper D, Kamal R, Kirti S: Efficacy and Toxicity of SBRT in Advanced Hepatocellular Carcinoma With Portal Vein Tumor Thrombosis: A Retrospective Study. Int J Radiat Oncol, 108:E622-E622

22. Rim CH, Kim CY, Yang DS, Yoon WS: Comparison of radiation therapy modalities for hepatocellular carcinoma with portal vein thrombosis: A metaanalysis and systematic review. Radiother Oncol 2018, 129(1):112-122.

23. Sun J, Zhang T, Wang J, Li W, Zhang A, He W, Zhang D, Li D, Ding J, Duan X: Biologically effective dose (BED) of stereotactic body radiation therapy (SBRT) was an important factor of therapeutic efficacy in patients with hepatocellular carcinoma $(</=5 \mathrm{~cm})$. BMC Cancer 2019, $19(1): 846$.

24. Su TS, Lu HZ, Cheng T, Zhou Y, Huang Y, Gao YC, Tang MY, Jiang HY, Lian ZP, Hou EC et al: Long-term survival analysis in combined transarterial embolization and stereotactic body radiation therapy versus stereotactic body radiation monotherapy for unresectable hepatocellular carcinoma $>5 \mathrm{~cm}$. BMC Cancer 2016, 16(1):834.

25. Scorsetti M, Comito T, Cozzi L, Clerici E, Tozzi A, Franzese C, Navarria P, Fogliata A, Tomatis S, D'Agostino G et al: The challenge of inoperable hepatocellular carcinoma (HCC): results of a single-institutional experience on stereotactic body radiation therapy (SBRT). J Cancer Res Clin Oncol 2015, 141(7):1301-1309.

26. Robbins JR, Schmid RK, Hammad AY, Gamblin TC, Erickson BA: Stereotactic body radiation therapy for hepatocellular carcinoma: Practice patterns, dose selection and factors impacting survival. Cancer Med 2019, 8(3):928-938.

27. Su TS, Luo R, Liang P, Cheng T, Zhou Y, Huang Y: A prospective cohort study of hepatic toxicity after stereotactic body radiation therapy for hepatocellular carcinoma. Radiother Oncol 2018, 129(1):136-142.

28. Liang SX, Zhu XD, Xu ZY, Zhu J, Zhao JD, Lu HJ, Yang YL, Chen L, Wang AY, Fu XL et al: Radiation-induced liver disease in three-dimensional conformal radiation therapy for primary liver carcinoma: the risk factors and hepatic radiation tolerance. Int J Radiat Oncol Biol Phys 2006, 65(2):426-434.

29. Liang SX, Huang XB, Zhu XD, Zhang WD, Cai L, Huang HZ, Li YF, Chen L, Liu MZ: Dosimetric predictor identification for radiation-induced liver disease after hypofractionated conformal radiotherapy for primary liver carcinoma patients with Child-Pugh Grade A cirrhosis. Radiother Oncol 2011, 98(2):265269.

30. Xu ZY, Liang SX, Zhu J, Zhu XD, Zhao JD, Lu HJ, Yang YL, Chen L, Wang AY, Fu XL et al: Prediction of radiation-induced liver disease by Lyman normaltissue complication probability model in three-dimensional conformal radiation therapy for primary liver carcinoma. Int J Radiat Oncol Biol Phys 2006, 65(1):189-195.

\section{Tables}

Table 1. Patient characteristics and treatment results of different treatment groups. 


\begin{tabular}{|c|c|c|c|c|c|c|c|}
\hline & & Befor PSM & & & After PSM & & \\
\hline Factor & Level & IMRT & SBRT & $P$ & IMRT & SBRT & $P$ \\
\hline $\mathbf{N}$ & & 154 & 133 & & 102 & 102 & \\
\hline \multirow[t]{2}{*}{ Sex } & male & 135 (87.7\%) & 120 (90.2\%) & 0.49 & $92(90.2 \%)$ & $92(90.2 \%)$ & 1.00 \\
\hline & femal & $19(12.3 \%)$ & $13(9.8 \%)$ & & $10(9.8 \%)$ & $10(9.8 \%)$ & \\
\hline age, median (IQR) & & $47(40,55)$ & $51(41,58)$ & 0.034 & $49(43,58)$ & $48(40,57)$ & 0.47 \\
\hline \multirow[t]{2}{*}{ HBV } & negative & $23(14.9 \%)$ & $23(17.3 \%)$ & 0.59 & $17(16.7 \%)$ & $18(17.6 \%)$ & 0.85 \\
\hline & positive & $131(85.1 \%)$ & $110(82.7 \%)$ & & $85(83.3 \%)$ & 84 (82.4\%) & \\
\hline \multirow[t]{5}{*}{ AFP } & $0-8$ & $26(16.9 \%)$ & $27(20.3 \%)$ & 0.47 & $17(16.7 \%)$ & 20 (19.6\%) & 0.53 \\
\hline & $8-100$ & 30 (19.5\%) & $22(16.5 \%)$ & & $19(18.6 \%)$ & $17(16.7 \%)$ & \\
\hline & $100-200$ & $13(8.4 \%)$ & $5(3.8 \%)$ & & $10(9.8 \%)$ & $4(3.9 \%)$ & \\
\hline & $200-400$ & $7(4.5 \%)$ & $7(5.3 \%)$ & & $5(4.9 \%)$ & $6(5.9 \%)$ & \\
\hline & $>400$ & $78(50.6 \%)$ & $72(54.1 \%)$ & & $51(50.0 \%)$ & $55(53.9 \%)$ & \\
\hline \multirow[t]{2}{*}{ CP-class } & $A$ & $139(89.6 \%)$ & 115 (86.4\%) & 0.80 & $89(87.3 \%)$ & 91 (89.2\%) & 0.60 \\
\hline & B & $15(10.4 \%)$ & $18(13.5 \%)$ & & $13(12.7 \%)$ & $11(10.8 \%)$ & \\
\hline \multirow[t]{3}{*}{ ALBI grade } & 1 & $61(39.6 \%)$ & $38(28.6 \%)$ & 0.002 & 39 (38.2\%) & 35 (34.3\%) & 0.12 \\
\hline & 2 & $93(60.4 \%)$ & 87 (65.4\%) & & $63(61.8 \%)$ & $63(61.8 \%)$ & \\
\hline & 3 & $0(0.0 \%)$ & $8(6.0 \%)$ & & $0(0.0 \%)$ & $4(3.9 \%)$ & \\
\hline \multirow[t]{4}{*}{ PVTT type* } & प & $20(12.9 \%)$ & $19 \rrbracket 14.8 \% \rrbracket$ & 0.093 & $13(12.7 \%)$ & $13(12.7 \%)$ & 0.536 \\
\hline & ૫ & $86(55.8 \%)$ & $74(55.6 \%)$ & & $58(56.9 \%)$ & $56(54.9 \%)$ & \\
\hline & $\square$ & $43(27.9 \%)$ & $40(30.1 \%)$ & & $29(28.4 \%)$ & 32 (31.3\%) & \\
\hline & ૫ & $5(3.2 \%)$ & $0(0 \%)$ & & $2(2.0 \%)$ & $0(0 \%)$ & \\
\hline \multirow[t]{2}{*}{ TACE refractory disease } & No & $98(63.6 \%)$ & $62(46.6 \%)$ & 0.004 & $59(57.8 \%)$ & $55(53.9 \%)$ & 0.57 \\
\hline & Yes & $56(36.4 \%)$ & $71(53.4 \%)$ & & $43(42.2 \%)$ & $47(46.1 \%)$ & \\
\hline PT, median (IQR) & & $12.8(12,14)$ & $13.3(12.6,14.3)$ & $<0.001$ & $13(12,14.1)$ & $13.15(12.4,14.2)$ & 0.29 \\
\hline Tbil, median (IQR) & & $16.1(11.2,23.5)$ & $15.2(10.9,20.6)$ & 0.18 & $15.35(11.1,24)$ & $15.2(10.4,20.6)$ & 0.36 \\
\hline albumin, median (IQR) & & $38.85(36,42)$ & $36.3(32.6,40.1)$ & $<0.001$ & $38.2(34.4,41.2)$ & $37(33.4,40.9)$ & 0.18 \\
\hline ALP, median (IQR) & & $131(96,182)$ & $124(97,172)$ & 0.54 & $123(91,167)$ & $122(94,172)$ & 0.96 \\
\hline BUN, median (IQR) & & $4.72(3.9,5.53)$ & $4.36(3.65,5.24)$ & 0.032 & $4.645(3.86,5.7)$ & $4.415(3.65,5.31)$ & 0.14 \\
\hline ALBI score, median (IQR) & & $\begin{array}{l}-2.540(-2.728 \\
-2.203)\end{array}$ & $\begin{array}{l}-2.292(-2.649 \\
-2.013)\end{array}$ & 0.001 & $\begin{array}{l}-2.532(-2.729 \\
-2.128)\end{array}$ & $\begin{array}{l}-2.40717(-2.693 \\
-2.113)\end{array}$ & 0.40 \\
\hline ALP, median (IQR) & & $131(96,182)$ & $124(97,172)$ & 0.54 & $123(91,167)$ & $122(94,172)$ & 0.96 \\
\hline size, median (IQR) & & $9(6.3,11.2)$ & $8.1(5.4,11)$ & 0.11 & $9.35(6.5,11.2)$ & $8.3(5.5,11)$ & 0.16 \\
\hline Total dose, median (IQR) & & $50.6(46,54)$ & $42(39,45)$ & $<0.001$ & $50.5(45,55)$ & $42(39,45)$ & $<0.001$ \\
\hline Fractions, median (IQR) & & $12(10,15)$ & $4(3,4)$ & $<0.001$ & $12(10,15)$ & $4(3,4)$ & $<0.001$ \\
\hline Per dose, median (IQR) & & $4(4,5)$ & $11.25(10.5,13)$ & $<0.001$ & $4(3,4.6)$ & $11.25(10.5,13)$ & $<0.001$ \\
\hline BED10, median (IQR) & & $73.1(67.2,79.0)$ & $89.7(86.1,95.7)$ & $<0.001$ & $72.8(61.6,79.0)$ & $89.7(86.1,95.7)$ & $<0.001$ \\
\hline $\begin{array}{l}\text { BED3 to nomal liver, median } \\
\text { (IQR) }\end{array}$ & & $27.6(19.2,35.6)$ & $35.0(25.9 ه 43.2)$ & $<0.001$ & $28.3(19.2-37.5)$ & $35.0(23.4-43.2)$ & $<0.001$ \\
\hline $\begin{array}{l}\text { Effective PGTV volume, median } \\
\text { (IQR) }\end{array}$ & & 535 (209-959) & 498 (232-927) & 0.26 & 535(209-959) & $504(303-927)$ & 0.87 \\
\hline os & median & $\begin{array}{l}10(\mathrm{Cl}, 7.918- \\
12.082)\end{array}$ & $\begin{array}{l}10(\mathrm{Cl}, 7.754- \\
12.246)\end{array}$ & 0.407 & $8(\mathrm{Cl}, 6.274-9.726)$ & $10(\mathrm{Cl}, 7.793-12.207)$ & 0.151 \\
\hline \multirow[t]{2}{*}{ (\%) } & $6 \mathrm{~ms}$ & 73.2 & 70.3 & & 73.5 & 72.4 & \\
\hline & $12 \mathrm{~ms}$ & 48.1 & 46.5 & & 42.9 & 45.1 & \\
\hline
\end{tabular}

Page 7/11 


\begin{tabular}{|c|c|c|c|c|c|c|c|}
\hline & $24 \mathrm{~ms}$ & 25.1 & 29.3 & & 23.6 & 29.8 & \\
\hline & $60 \mathrm{~ms}$ & 10.7 & 11.3 & & 7.6 & 13.2 & \\
\hline PFS & median & 6(Cl,3.868-8.132) & $6(\mathrm{Cl}, 5.161-6.839)$ & 0.424 & 6(Cl,3.723-8.277) & $6(\mathrm{Cl}, 4.939-7.061)$ & 0.744 \\
\hline \multirow[t]{4}{*}{ (\%) } & $6 \mathrm{~ms}$ & 52.3 & 51.3 & & 53.9 & 54.5 & \\
\hline & $12 \mathrm{~ms}$ & 30.6 & 21.6 & & 29.3 & 19.3 & \\
\hline & $24 \mathrm{~ms}$ & 20.7 & 10.0 & & 21.8 & 12.0 & \\
\hline & $60 \mathrm{~ms}$ & 8.7 & 8.3 & & 7.5 & 9.6 & \\
\hline LC & $6 \mathrm{~ms}$ & 84.5 & 87.0 & 0.498 & 85.2 & 87.4 & 0.191 \\
\hline \multirow[t]{3}{*}{ (\%) } & $12 \mathrm{~ms}$ & 62.6 & 64.8 & & 56.5 & 65.2 & \\
\hline & $24 \mathrm{~ms}$ & 58.1 & 54.6 & & 52.1 & 62.1 & \\
\hline & $60 \mathrm{~ms}$ & 52.7 & 54.6 & & 47.4 & 62.1 & \\
\hline IC & median & $9(\mathrm{Cl}, 7.112-12.888)$ & $\begin{array}{l}\text { 11(Cl,7.797- } \\
14.203)\end{array}$ & 0.094 & $\begin{array}{l}8(\mathrm{Cl}, 4.462- \\
11.538)\end{array}$ & $11(\mathrm{Cl}, 7.827-14.173)$ & 0.144 \\
\hline \multirow[t]{4}{*}{ (\%) } & $6 \mathrm{~ms}$ & 61.8 & 75.4 & & 61.4 & 75.1 & \\
\hline & $12 \mathrm{~ms}$ & 44.3 & 46.3 & & 45.7 & 45.8 & \\
\hline & $24 \mathrm{~ms}$ & 35.6 & 33.0 & & 39.0 & 35.9 & \\
\hline & $60 \mathrm{~ms}$ & 26.0 & 26.4 & & 26.8 & 28.7 & \\
\hline
\end{tabular}

Table 2. Treatment outcomes of radiation therapy for hepatocellular carcinoma with PVTT. 


\begin{tabular}{|c|c|c|c|c|c|c|c|c|c|c|c|}
\hline \multirow[t]{2}{*}{ Authors } & \multirow[t]{2}{*}{$\begin{array}{l}\text { Study } \\
\text { design }\end{array}$} & \multirow[t]{2}{*}{ Technique } & \multirow{2}{*}{$\begin{array}{l}\text { Number } \\
\text { of } \\
\text { cases }\end{array}$} & \multirow[t]{2}{*}{$\begin{array}{l}\text { BCLC } \\
\text { stage }\end{array}$} & \multirow{2}{*}{$\begin{array}{l}\text { Median } \\
\text { per } \\
\text { dose } \\
\text { (range) }\end{array}$} & \multirow[t]{2}{*}{ Fraction } & \multirow{2}{*}{$\begin{array}{l}\text { Median } \\
\text { total } \\
\text { dose } \\
\text { (range) }\end{array}$} & \multirow[t]{2}{*}{$\begin{array}{l}\text { Median } \text { BED }_{10} \\
\text { (range) }\end{array}$} & \multirow[t]{2}{*}{$\begin{array}{l}\text { combined/previous } \\
\text { treatment }\end{array}$} & \multicolumn{2}{|l|}{ os } \\
\hline & & & & & & & & & & $1 y$ & 2 \\
\hline $\begin{array}{l}\text { Kim, } \\
2013\end{array}$ & retrospective & IMRT & 35 & C & $\mathrm{NA}^{*}$ & $\begin{array}{l}10 \mathrm{~F}, 5 \mathrm{~F} / \\
\text { per week }\end{array}$ & $\begin{array}{l}50(45- \\
60)\end{array}$ & 75 ( 65.3-96 ) & $\begin{array}{l}\text { Chemotherapy with } \\
\text { capecitabine }\end{array}$ & 51.4 & 2 \\
\hline $\begin{array}{l}\text { Chen, } \\
2014\end{array}$ & prospective & IMRT & 24 & C & $2-2.5$ & $\begin{array}{l}5 \mathrm{~F} / \text { per } \\
\text { week }\end{array}$ & $\begin{array}{l}50(40- \\
60)\end{array}$ & NA & Sorafenib & NA & 3 \\
\hline $\begin{array}{l}\text { Hou, } \\
2016\end{array}$ & retrospective & IMRT & 54 & $\mathrm{C}$ & $2.5-4$ & $\begin{array}{l}\text { average } \\
19.4 \mathrm{~F}\end{array}$ & $\begin{array}{l}60(40- \\
66)\end{array}$ & 72.35 & NA & 59.3 & $\mathrm{~N}$ \\
\hline Im, 2017 & retrospective & $\begin{array}{l}\text { 3D- } \\
\text { CRT/IMRT }\end{array}$ & 985 & C & $\begin{array}{l}2.5 \\
(1.8- \\
17)\end{array}$ & NA & $\begin{array}{l}45(12- \\
66)\end{array}$ & )$^{48.75(13.0-114.75}$ & $\begin{array}{l}\text { TACE/TACI } \\
\text { /HAIC(66.7) }\end{array}$ & 43.3 & 2 \\
\hline Xi, 2013 & retrospective & SBRT & 41 & C & $6(5-8)$ & $\begin{array}{l}6 \mathrm{~F} / 2 \\
\text { weeks }\end{array}$ & $\begin{array}{l}36 \\
(30- \\
48)\end{array}$ & NA & sorafenib(34.1) & 50.3 & $\mathrm{~N}$ \\
\hline $\begin{array}{l}\text { Bettinger, } \\
2019\end{array}$ & retrospective & SBRT & 22 & C & NA & $\begin{array}{l}\text { median } \\
7(3-12)\end{array}$ & $\begin{array}{l}44 \\
(21- \\
66)\end{array}$ & $84.4(36-124)$ & NA & NA & $\mathrm{N}$ \\
\hline $\begin{array}{l}\text { Yang, } \\
2019\end{array}$ & retrospective & SBRT & 54 & $\mathrm{C}$ & $6-12.5$ & $4-5$ & $\begin{array}{l}45 \rrbracket 40- \\
48 \rrbracket\end{array}$ & $\begin{array}{l}< \\
65: 25.9 \% ; \geq 65: 74.0 \%\end{array}$ & sorafenib & 34.9 & 1 \\
\hline \multirow[t]{2}{*}{$\begin{array}{l}\text { Chopra, } \\
2019\end{array}$} & retrospective & SBRT & 21 & $\begin{array}{l}\mathrm{B} \\
(57.1 \%) /\end{array}$ & NA & $6(5-6)$ & $\begin{array}{l}42(25- \\
54)\end{array}$ & $59.5(23.4-100)$ & TACE(66.7) & 51 & 1 \\
\hline & & & & $\begin{array}{l}\mathrm{C} \\
(42.9 \%)\end{array}$ & & & & & & & \\
\hline \multirow[t]{2}{*}{$\begin{array}{l}\mathrm{Liu}_{\eta \prime} \\
2020\end{array}$} & retrospective & SBRT & 37 & $\begin{array}{l}\text { B } \\
(32.4 \%) /\end{array}$ & NA & $5(3-5)$ & 35 & $60(45-100)$ & TACE (40.5\%) & $71 \%$ & $\mathrm{~N}$ \\
\hline & & & & $\begin{array}{l}\mathrm{C} \\
(70.2 \%)\end{array}$ & & & & & & & \\
\hline $\begin{array}{l}\text { Yadav, } \\
2020\end{array}$ & retrospective & SBRT & 30 & C & NA & $6(5-6)$ & $\begin{array}{l}48(32- \\
50)\end{array}$ & NA & NA & 60 & $\mathrm{~N}$ \\
\hline \multirow[t]{2}{*}{$\begin{array}{l}\text { Present } \\
\text { study }\end{array}$} & retrospective & IMRT & 154 & C & )$^{4(2-7}$ & $\begin{array}{l}\text { median } \\
12(7- \\
25), 5 \mathrm{~F} / \\
\text { per week }\end{array}$ & $\begin{array}{l}51(24- \\
64)\end{array}$ & 73 (31-95) & TACE $(36.4 \%)$ & 48.1 & 2 \\
\hline & & SBRT & 133 & $\mathrm{C}$ & $\begin{array}{l}11.3(7- \\
15)\end{array}$ & $3-5$ & $\begin{array}{l}42(30- \\
50)\end{array}$ & $90(36-116)$ & TACE(53.4\%) & 46.5 & 2 \\
\hline
\end{tabular}

*Abbreviation[NA=not available

\section{Figures}



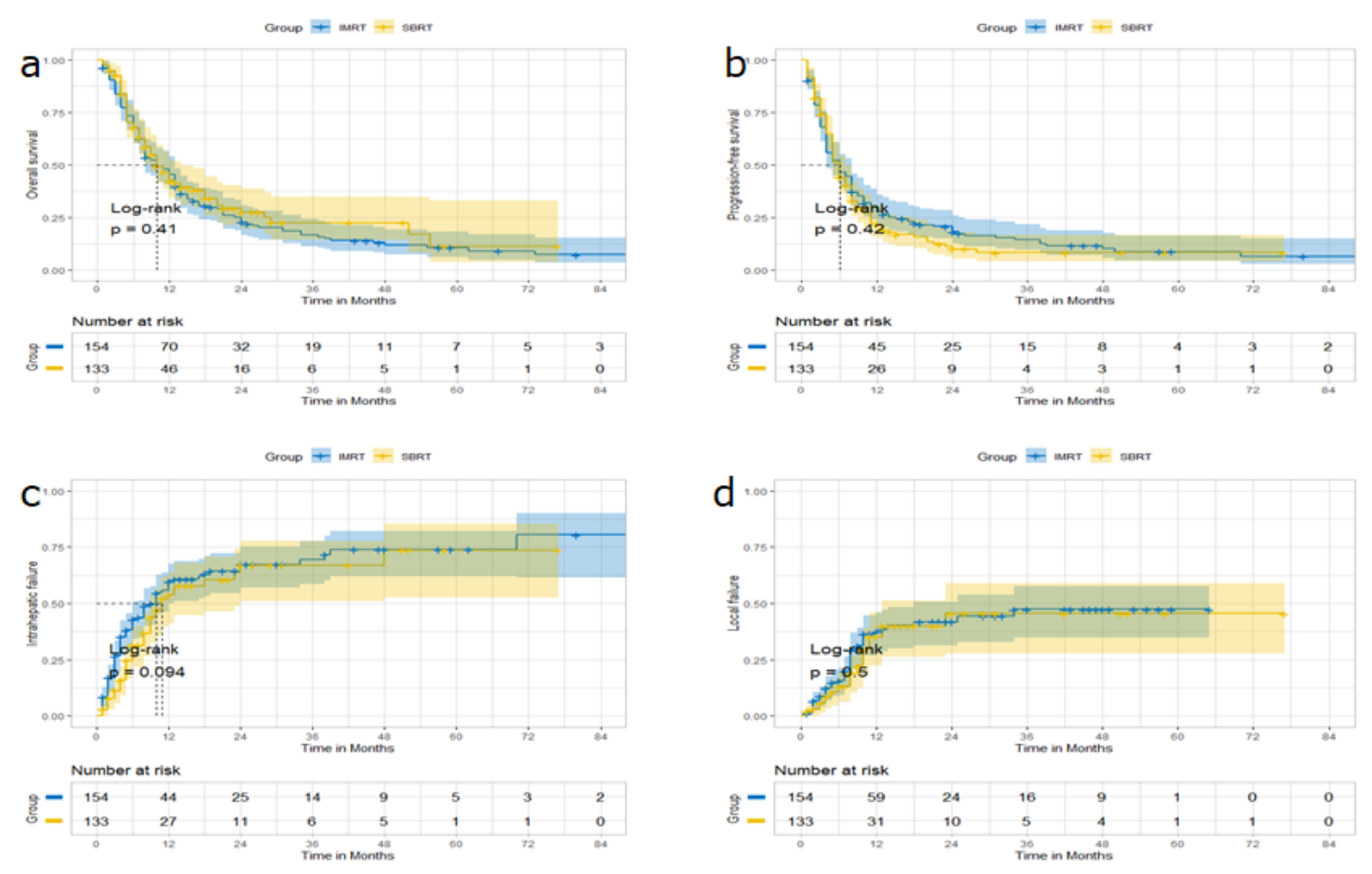

Figure 1

Before propensity matching, Kaplan-Meier curve of SBRT versus IMRT. (a) overall survival; (b) progression-free survival; (c) intrahepatic failure; (d) local control
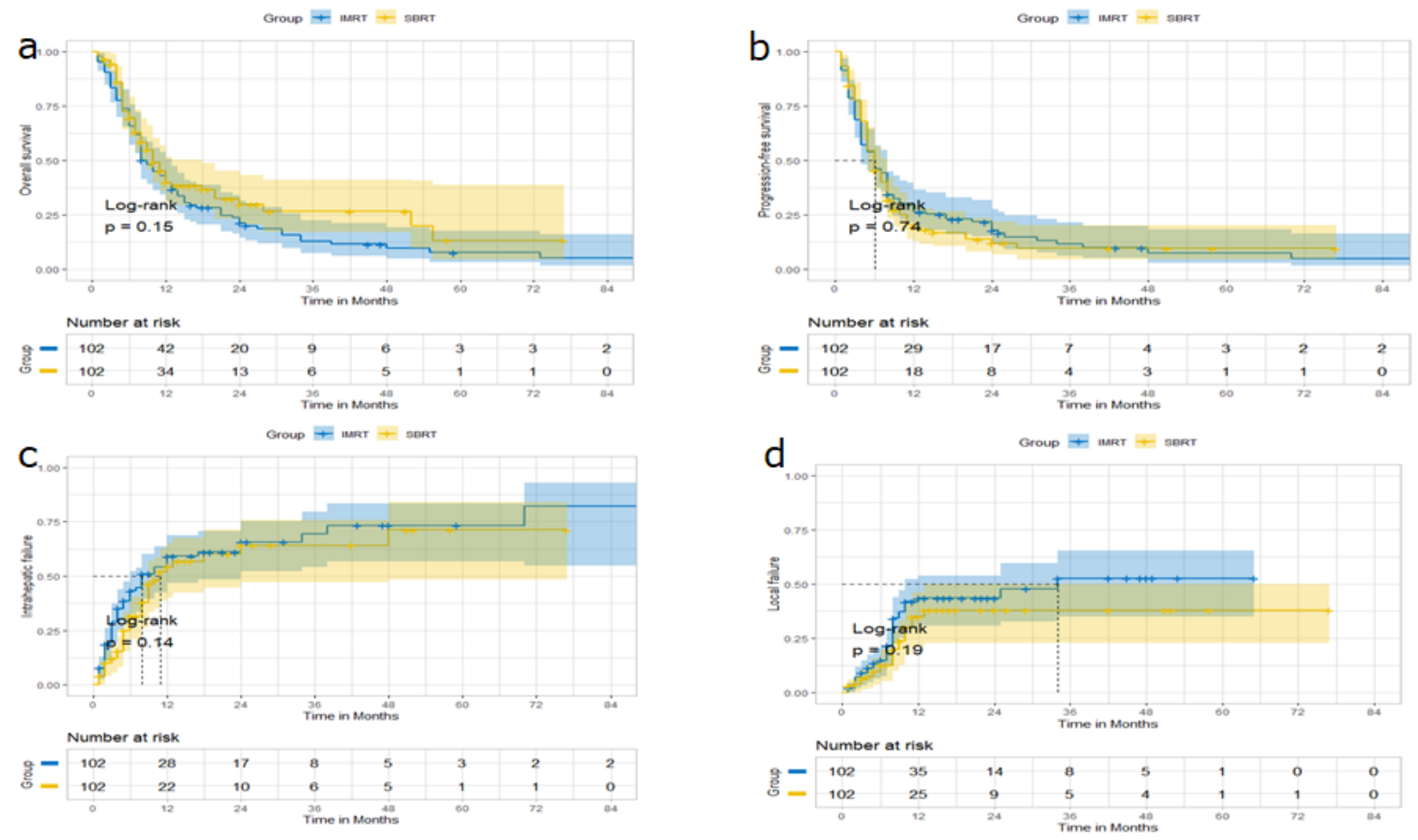

Figure 2

After propensity matching, Kaplan-Meier curve of SBRT versus IMRT. (a) overall survival; (b) progression-free survival; (c) intrahepatic failure; (d) local control 

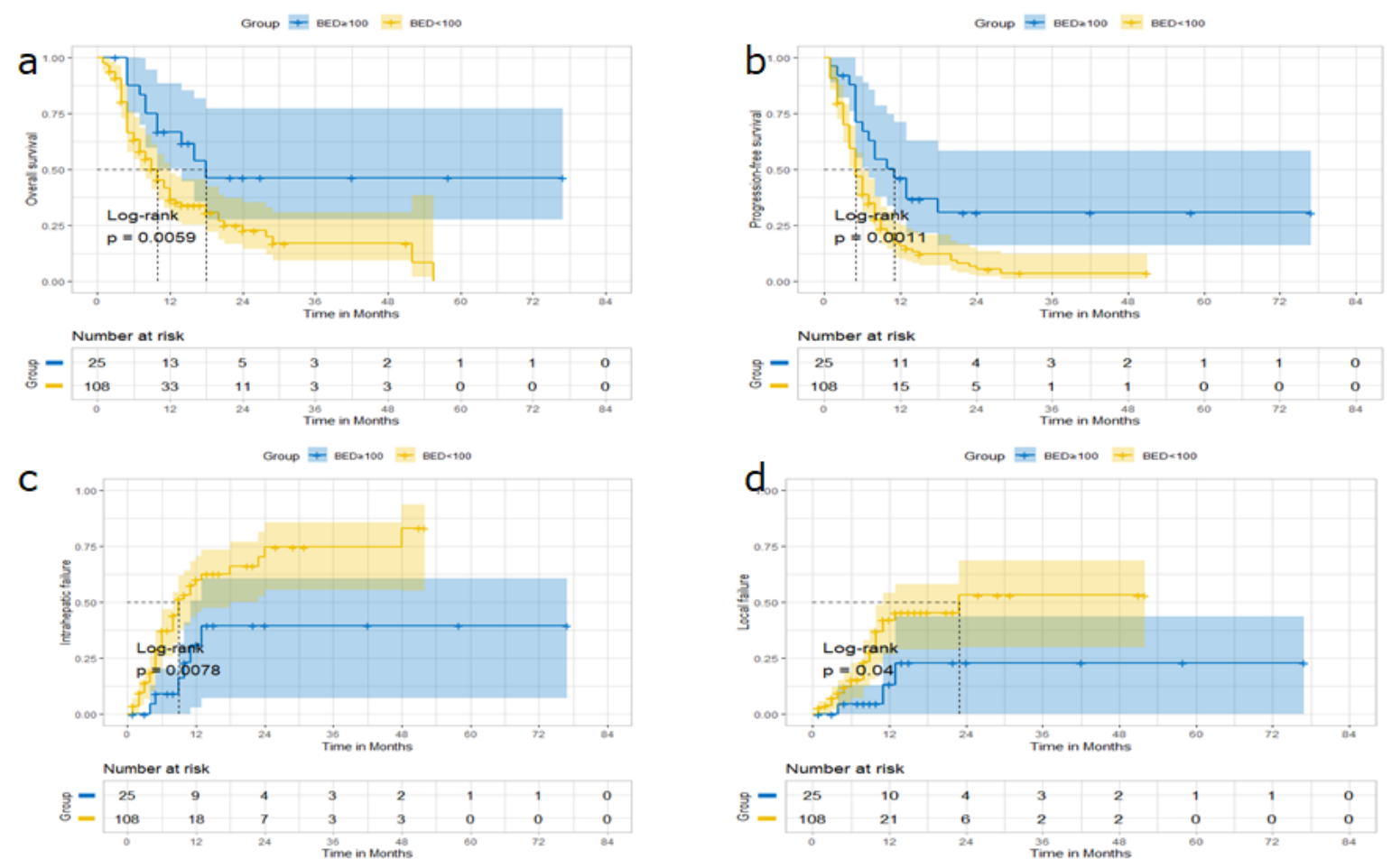

\section{Figure 3}

Kaplan-Meier curve with a BED cutoff value of 100Gy in unmatched SBRT group. (a) overall survival; (b) progression-free survival; (c) intrahepatic failure; (d) local control

\section{Supplementary Files}

This is a list of supplementary files associated with this preprint. Click to download.

- Supplementarylnformation2021.1.281.docx

- floatimage1.png 